\title{
Embarazo posterior a vaginoplastia por atresia
}

\author{
ISS - CLINICA RAFAEL URIBE - CALI
}

Dres.: Nestor H. Amorocho P. y Bension Goldenberg

\section{INTRODUCCION}

La vagina se forma de dos estructuras separadas: el tercio inferior arranca del seno urogenital y la porción superior de los conductos de Müller fusionados. Esta última formación primordial forma también el cérvix, el útero y las trompas de Falopio.

La canalización de la vagina ocurre como resultado de degeneración de las células centrales de un cordón epitelial, el cual se deriva de la unificación de los mencionados conductos iniciales. La falla en el desarrollo y unión del sistema mulleriano podría dar como resultado ausencia de la porción superior de la vagina tanto como del ú tero (1).

En pacientes con ausencia congénita de vagina, el defecto generalmente incluye ausencia de genitales internos. En tales condiciones, la menstruación y la concepción no pueden ocurrir.

La falla en la degeneración de las células centrales del cordón epitelial formado por fusión del seno urogenital con el canal útero vaginal puede resultar en un defecto de canalización de la vagina.
Este tipo de anomalía compromete aproximadamente el 8\% de los casos de ausencia de vagina. En estas circunstancias, donde existe vagina muy pobremente canalizada y al parecer una especie de fístula que comunica el tercio inferior con la porción superior vaginal, la menstruación y la concepción, teóricamente, pueden ocurrir.

Veintitres pacientes, reportadas hasta 1959, habían concebido después de operación para reconstruir "La ausencia congénita de la vagina" (2).

El caso que presentamos si bien es cierto no corresponde a una agenesia vagina! (ausencia congénita de vagina), podríamos denominarlo como atresia iatrogénica vaginal y la historia del ISS, Caja Seccional Valle, es así:

H. C. No. 844936

Fecha: Mayo 23 de 1980

Nombre: M. A. D.

Edad: 18 años

M. de C.: No ha podido tener relaciones sexuales. 
Enfoque Actual: Hace un mes se casó $y$ no ha tenido coito por imposibilidad de penetración de pene. Vagina ocluída por cicatriz, producto de un accidente automovilístico, cuando tenía un año de edad. Nunca ha tenido menstruaciones periódicas, pero ocasionalmente ha presentado leves pérdidas sanquíneas por vagina.

Mayo 26 de 1980: Consulta Ginecología: "Hay estenosis cicatricial, incompleta en introito. Cx: Plastia vulvar".

Junio 3 de 1980: Consulta Ginecología: "T.V.: imposible por estenosis. Se pide radiografía de pelvis".

Junio 18 de 1980: Rayos X: "Diastasis leve de pubis y fractura antigua de borde superior, separada y con dos fragmentos en los extremos. Antigua fractura de rama inferior. En placa oblicua se ve una densidad .........".

Cx: Se pide laparoscopia y se remite a traumatología para concepto, antes de intentar plastia.

Junio 23 de 1980: Laparoscopia diagnóstica: Peritoneo, ligamentos redondos y útero-sacros, útero: normales. Ovario derecho: normal, actividad folicular. Fibroma ovárico $2 \times 2 \mathrm{cms}$. Trompa derecha: Normal. Ovario izquierdo: Oculto Trompa izquierda: Oculta. Permeabilidad tubaria: no se practicó por obliteración vaginal.

Diagnóstico final: Obliteración y fibrosis vaginal de origen traumático.

Recomendaciones: No hay masa pélvica accesoria. Practicar neovagina con injerto libre dermo-epidérmico (No hacer laparatomía).

Septiembre 10 de 1980: Se solicita prórroga de protección del ISS a Dpto. Médico, por fin de servicios para la afiliada, autorización de cirugía.
Septiembre 16 de 1980: Exámenes de laboratorio prequirúrgicos: $\mathrm{Hb}$., $\mathrm{Ht}$., T. de coagulación y sangría, Urea, glicemia: normales. Se programa cirugía.

Octubre 13 cie 1980: Cirugía: Con la técnica de Mc Indoe (3) tomando colgajo para injerto con dermátomo de la cara postero-lateral de muslo se hace tunelización de vagina, dejando molde elaborado con madera de balso. Se ordena tratamiento estrogénico, local (crema) y sistémico (estrógenos conjugados: $3.75 \mathrm{mgs} / \mathrm{d}$ ía).

\section{Evolución}

Diciembre 5 de 1980: Se presenta fibrosis y cicatrización retráctil en introito sobre rama derecha de pubis, con tendencia a estenosis marcada de la neovagina.

Se programa para nueva cirugía en enero de 1981.

Enero 28 de 1981: Vagina estenosada. Permite apenas tacto unidigital forzado Presentó menstruación enero 22 de 1981, diciembre 23 de 1980.

Se programa nueva cirugía con técnica combinada abdomino-perineal, canalización retrógrada de vagina (5), (6).

De nuevo se solicita autorizar prórroga de servicios para efectuar cirugía plástica y ginecológica.

Marzo 31 cie 1981: Cirugía: Colocando a la paciente en posición ginecológica, piernas bajas para operación abdominoperineal, se efectúa incisión transversa supra-púbica (incisión de Pfannenstiel, modificada) (4).

Disección de fondo de saco vesicouterino, desprendimiento de vejiga hasta zona vaginal. Se abre vagina, se visualiza 
cervix, y efectuando disección roma se perfora hacia periné, siguiendo trayecto vaginal, para llegar a introito. Con dilatador de Hegar se amplia el túnel obtenido y por vía vaginal se hace desprendimiento de colgajos de mucosa vaginal (tercio superior) que se fijan a nivel de introito con catgut.

\section{Evolución}

Post-operatorio satisfactorio. Se ordena estrógeno terapia local y oral. Salida: abril 2 de 1981 .

Abril 29 de 1981: Hay estenosis a nivel de introito vaginal por fibrosis cicatricial, que dificulta el coito y produce dispareunia. Se programa para corrección quirúrgica.

Junio 8 de 1981: Cirugía: Se efectúa colporrafía resecando tejido fibrosado en lado izquierdo de introito y efectuando cierre en sentido transversal para ampliar introito vaginal.

\section{Evolución}

Septiembre 2 de 1981: Presentó menstruación. F. U. R. Agosto 1 de 1981. Tomó anovulatorios (automedicación) por un mes. Examen ginecológico vagina normal, cuello sano, $T$. V.: utero en A. F. normal.

Diciembre 23 de 1981: F. U. R. Dic. 14 de 1981. Flujo vaginal de mal olor. Al exámen ginecológico: en horquilla vulvar, lado derecho se encuentra tumoración papilar, tipo granuloma y secreción purulenta. Se ordena antibiótico local y sistémico.

Enero 13 de 1982: Extirpación de granuloma y cauterización.

Mayo 12 de 1982: F. U. R. Enero 28 de 1982. Sintomatología y signos de embarazo. Al exámen ginecológico se palpa utero aumentado para embarazo de 12-14 semanas. Se remite a control prenatal programa de alto riesgo.

Octubre 25 de 1982: Cirugía: Cesárea. Embarazo 39 semanas. Se obtiene producto femenino. Peso $2.500 \mathrm{gr}$ talla: 46 cms-Apgar: 9/10. (4).

Junio 8 de 1983: Amenorrea. F.U.R. Febrero 16 de 1983. Embarazo de aproximadamente 15 semanas. Solamente presentó menstruación en febrero, hasta entonces estuvo en amenorrea de lactancia.

Septiembre 7 de 1983: Control. Embarazo 24 semanas. Evolución normal. F.P.P.: se calcula para diciembre 23 de 1983, post-Ecografía.

\section{RESUMEN}

Se presenta un caso de ausencia de vagina, que aunque no corresponde a defecto congénito, se trata de atresia iatrogénica debida a traumatismo por accidente automoviliario de la paciente cuando ten ía un año de edad. Se efectuó cirugía reparadora $y$ después de tres intervenciones se logró estado funcional de vagina para obtener embarazo posterior que termina por cesárea y luego un nuevo embarazo que cursa normalmente.

\section{PREGNANCY AFTER VAGINOPLASTIA}

\section{SUMMARY}

The article presents the case of a woman without a vagina due to iatrogenic atresia caused by trauma post automobile accident when the patient was one year-old. The patient underwent repair surgery and after three interventions the vagina was functional. The first pregnancy ended up in a Cesarean section and the second one is currently underway; the patient is in good condition. 


\section{BIBLIOGRAFIA}

1. AMOROCHO, N.H., GOLDENBERG, B.: Malformación congénita del sistema reproductivo -Síndrome de Rokitansky-. Kuster Hauser. Rev. Col. Obst. y Ginec., Vol. XXIX No. 4 julio-agosto, 1978.

2. PILKINGTON, J.W.: Pregnancy and spontaneous delivery following operation for congenital atresia of the vagina. Am. J. Obst. \& Gynec. 78: 804, 1959.

3. WHARTON-Mc. INDOE.: Gynecology and Obstetrics. Vol. II. Chapter 39. Harper and Row. publishers Inc., 1976.
4. AMOROCHO, N.H., RESTREPO, H.: Cesárea por incisión transversa suprapúbica. Rev. Colombiana Obstetricia y Ginecología; Vol. XXVII No. 3; 164-170, mayo junio 1976.

5. SARGIS, H., and OTHERS: Construction of a functional vagina; a New Surgical Approach in Congenital Absence of the vagina, Am. J. Obst. \& Gynec. 79: 67, 1960.

6. SHEARES, B. H.: Congenital Atresia of the vagina. A New technique for Tunnelling the Space Between Bladder and Rectum and Construction of the New Vagina by a Modified Wharton Technique, J. Obst. \& Gynec. Brit. Emp. 67: 24, 1960. 